\title{
REVIEW
}

\section{Why are hematopoietic stem cells so 'sexy'? on a search for developmental explanation}

\author{
MZ Ratajczak ${ }^{1,2}$
}

Evidence has accumulated that normal human and murine hematopoietic stem cells express several functional pituitary and gonadal sex hormones, and that, in fact, some sex hormones, such as androgens, have been employed for many years to stimulate hematopoiesis in patients with bone marrow aplasia. Interestingly, sex hormone receptors are also expressed by leukemic cell lines and blasts. In this review, I will discuss the emerging question of why hematopoietic cells express these receptors. A tempting hypothetical explanation for this phenomenon is that hematopoietic stem cells are related to subpopulation of migrating primordial germ cells. To support of this notion, the anatomical sites of origin of primitive and definitive hematopoiesis during embryonic development are tightly connected with the migratory route of primordial germ cells: from the proximal epiblast to the extraembryonic endoderm at the bottom of the yolk sac and then back to the embryo proper via the primitive streak to the aorta-gonado-mesonephros (AGM) region on the way to the genital ridges. The migration of these cells overlaps with the emergence of primitive hematopoiesis in the blood islands at the bottom of the yolk sac, and definitive hematopoiesis that occurs in hemogenic endothelium in the embryonic dorsal aorta in AGM region.

Leukemia (2017) 31, 1671-1677; doi:10.1038/leu.2017.148

\section{INTRODUCTION}

There are still two major unknowns that have not been fully elucidated in hematopoiesis. The first is the phenotype of the cells that become specified to hemato/lymphopoiesis during embryogenesis and the second is the phenotype of the most primitive precursor of hematopoietic stem cells (HSCs) residing in adult hematopoietic organs.

The origin of hematopoiesis is biphasic, starting from primitive hematopoiesis and culminating in definitive hematopoiesis, ${ }^{1,2}$ and in the developing embryo two separate anatomical sites have been identified where these processes occur. Specifically, during the primitive phase of hematopoiesis, the first hematopoietic precursor cells are identified outside the embryo proper in the socalled hematopoietic islands at the bottom of the yolk sac. ${ }^{1,3-6}$ The blood islands are believed to develop from putative hemangioblasts, which give rise to endothelial precursors and $\mathrm{HSCs}^{7}$ Definitive hematopoiesis is observed later in embryonic development when the first HSCs become specified in the dorsal aorta wall in the so-called hematogenic endothelium. ${ }^{8,9}$ This area is part of a wider anatomical area of the embryo known as the aortagonado-mesonephros (AGM) region. What is important for the subject of this review, is that initiation of both primitive and definitive hematopoiesis is tightly connected with the migration of primordial germ cells (PGCs). ${ }^{5,6,9-12}$ In this review, I will present the concept that a subpopulation of cells related to migrating PGCs could be responsible for establishing hematopoiesis in both places.

Returning to the second issue, it is accepted that not all stem cells with hematopoietic potential are equal, and some very rare HSCs are more developmentally primitive than others. Therefore, the quest for the most primitive HSCs still continues, and several potential candidates have been proposed. ${ }^{13,14}$ What is important in this review, I will present the concept that a rare population of PGC-descendant stem, cells residing in adult tissues, termed very small embryonic-like stem cells (VSELs), are precursors of longterm repopulating HSCs (LT-HSCs). ${ }^{15,16}$ We envision that VSELs could be (i) the main precursor or (ii) a reserve source of LT-HSCs. $^{17}$

In sum, the expression of functional sex hormone receptors on PGCs, VSELs and HSCs connects these two provocative concepts, ${ }^{12,17-19}$ and this somewhat challenging point of view about hematopoiesis will be critically discussed in the current review.

\section{EVIDENCE FOR THE PRESENCE OF CELLS WITH GERMLINE POTENTIAL IN ADULT BM}

The presence of germline precursor cells in adult BM has been proposed by several investigators. For example, SSEA- $1^{+}$Oct$4^{+}$Stella $^{+} \mathrm{Mvh}^{+}$cells, isolated from murine BM with anti-SSEA-1 immunomagnetic beads, differentiated in the presence of BMP-4 (bone morphogenetic factor 4 ) into gamete precursors. ${ }^{20}$ It has also been proposed that BM-derived Oct $-4^{+} \mathrm{Mvh}^{+} \mathrm{Dazl}^{+}$Stella ${ }^{+}$ putative germ cells affect the recurrence of oogenesis in mice sterilized by chemotherapy. ${ }^{21,22}$ In another study, Oct- $4^{+} \mathrm{Mvh}^{+}$ $\mathrm{Stella}^{+}$cells isolated from the BM of male Stra8-GFP transgenic mice, expressed several molecular markers of spermatogonial stem cells and spermatogonia. ${ }^{23}$ Moreover, BM-derived GFP ${ }^{+}$ transgenic Oct- $4^{+}$SSEA- $1 / 3 / 4^{+}$cells isolated from the BM of GFP ${ }^{+}$ chicken gave rise to functional sperm after injection into chicken

\footnotetext{
${ }^{1}$ Stem Cell Institute, James Graham Brown Cancer Center, University of Louisville, Louisville, KY, USA and ${ }^{2}$ Department of Regenerative Medicine, Warsaw Medical University, Warsaw, Poland. Correspondence: Professor MZ Ratajczak, Stem Cell Institute, James Graham Brown Cancer Center, University of Louisville, 500 S. Floyd Street, Rm. 107, Louisville, KY 40202, USA. 
testes. ${ }^{24}$ Interestingly, in direct mutagenesis studies, it has also been demonstrated that BM cells exposed to methylchloranthrene may give rise to germline tumors. ${ }^{25}$ Finally, in a very recent study, murine BM-derived VSELs have been demonstrated to differentiate into germline cells. ${ }^{18}$ Below, I will discuss the potential developmental link between PGCs and hematopoiesis.

\section{PGCS AND HEMATOPOIESIS—SUPPORTIVE EVIDENCE FOR THE EXISTENCE OF A LINK}

PGCs are specified in the proximal epiblast, which is an anatomical region derived from the pluripotent stem cell cluster in the inner cell mass of the blastocyst and can be anatomically distinguished shortly after implantation of the blastocyst into the uterus. ${ }^{26}$ The epiblast gives rise to all three germ layers (meso-, ecto-, and endoderm) as well as gametes. What is intriguing and relevant for this review, PGCs are the very first stem cells to become specified in the mouse proximal epiblast, 6.25 days post coitum (dpc). ${ }^{27}$ Shortly after this, PGCs leave the developing embryo proper and migrate to the extraembryonic endoderm toward the yolk sac at the bottom of the allantois, where they become visible as a group of 50 alkaline phosphatase-positive cells at $7.5 \mathrm{dpc}^{28}$ This is around the time when the first hemangioblasts and hematopoietic islands emerge in this area of the embryo. ${ }^{29}$ Subsequently, PGCs, which are continuously amplified during the migration process, leave the extraembryonic endoderm and return to the embryo proper. They then enter the so-called primitive streak and migrate towards the genital ridges, where ultimately, between 12.5 and $14.5 \mathrm{dpc}$, they will settle and give rise to gametes. ${ }^{30}$ Before this occurs, PGCs on their way to the genital ridges cross the AGM region on day $11 \mathrm{dpc}$, as mentioned above. 5,9,30,31

During their migration in extraembryonic tissue and later in the embryo proper, PGCs not only amplify in number but also change the expression of certain genes, so that, based on their molecular signature, we can distinguish three developmental stages of these cells: (i) early-migrating, (ii) migrating and (iii) post-migrating PGCs. ${ }^{11,31}$ While post-migrating PGCs ultimately establish gametogenesis, early PGCs, which I will discuss below, could theoretically give rise to hemangioblasts and initiate primitive hematopoiesis in the yolk sac blood islands, and late-migratory PGCs could give rise to definitive hematopoiesis in the AGM region, where the first HSCs can be identified that are associated with the aortic endothelium. ${ }^{30-32}$

Currently, it is widely accepted that-due to the initiation of circulation via the blood stream, which requires a beating heartHSCs from the blood islands colonize different areas of the endothelium in large vessels, including the dorsal aortic wall in AGM region. ${ }^{9}$ In support of this mechanism, murine Ncx1-KO embryos, which do not develop a beating heart by $8.25 \mathrm{dpc}$ but still continue to develop until $10 \mathrm{dpc}$, do not initiate definitive hematopoiesis. 2,33 Specifically, while there was no significant difference in the number of hematopoietic precursors in the yolk sacs from wild type and Ncx1-KO embryos, the embryo proper, including the AGM region, was nearly devoid of HSCs in mutant animals. ${ }^{2,34}$ However, this concept that HSCs from the yolk sac may specify into definitive HSCs and colonize aortic endothelium, does not preclude the possibility that the aortic endothelium could be colonized by PGC-derived cells migrating through the AGM region by $11 \mathrm{dpc}$ in mice. ${ }^{30-32}$ For the initiation of definitive hematopoiesis in the aortic endothelium, it is known that there is an effect induced by shear forces from active blood flow. ${ }^{35}$ Again, we cannot preclude that these shear forces act on migrating PGC-derived cells that infiltrate the aortic endothelium.

In support of the intriguing concept that HSCs may be derived from PGCs, ${ }^{12,36,37}$ it has been demonstrated that PGCs isolated from murine embryos, stem cells isolated from murine testes ${ }^{38}$ and certain teratocarcinoma cell lines ${ }^{39}$ can be specified into HSCs. By contrast, the 'hematopoietic' functional erythropoietin receptor
(EpoR) is expressed in germline-derived tumors such as murine and human teratocarcinoma and gonadal tumor cell lines. ${ }^{40}$ Moreover, there are reports on the clonal origin of both teratomas and germline leukemia tumors. ${ }^{41-43}$

An important factor in the development of PGCs is the transforming growth factor $\beta$-related factor bone morphogenetic protein 4 (BMP-4). ${ }^{44}$ It has been reported that BMP-4 is expressed in the AGM coincident with the emergence of HSCs and also stimulates postnatal HSCs in in vitro assays. ${ }^{45}$ Moreover, in an elegant, recently published paper employing mouse PGCs marked by the transgene green fluorescence protein (GFP) driven by the germ cell-specific promoter or enhancer region of the Oct3/4 gene, the authors found that the cell population moving toward the gonadal ridges and usually identified as PGCs encompasses a subset of cells co-expressing several germ cell and hematopoietic markers with hematopoietic activity. These cells that settled in the AGM region, expressed various Oct3/4-positive cell populations showing distinct expression of PGC markers (Blimp-1, AP, Tg-1, Stella) and at the same time several proteins and genes for hematopoietic precursors, such as CD34, CD-41, FLK-1, Brachyury, Hox-B4, Scl/Tal-1 and Gata-2. In particular, Oct3/4-GFP-weak CD34-weak/high cells exhibited robust hematopoietic colonyforming activity in vitro. ${ }^{30}$

\section{FROM PGCS TO VSELS-HOW MUCH EVIDENCE EXISTS?}

It has been proposed that adult tissues, including murine and human bone marrow (BM), human umbilical cord blood (UCB), and mobilized peripheral blood (mPB), harbor a population of very rare small stem cells with pluri- or multi-potential differentiation. In fact, it has been proposed that during embryogenesis, some stem cells related to migrating PGCs escape specification into tissue-committed stem cells, retain their pluripotent character and survive as a population of very small embryonic-like stem cells (VSELs) into adulthood, thus forming a reserve 'back-up pool' of stem cell precursors for adult issues. ${ }^{17,46,47}$

VSELs are slightly smaller than mature erythrocytes. ${ }^{48}$ The small size of these cells ( 3-5 $\mu \mathrm{m}$ in mice and 4-7 $\mu \mathrm{m}$ in humans) and the paucity of mitochondria are signs of their quiescence and low metabolic activity. BM-derived VSELs are, in fact, very rare ( 0.01$0.001 \%$ of nucleated BM cells) and have been shown to be precursors of several types of stem cells, including HSCs, mesenchymal cells (MSCs), ${ }_{14,50}$ endothelial progenitors, ${ }^{51,52}$ lung alveolar epithelial cells, ${ }^{53,54}$ cardiomyocytes ${ }^{55}$ and gametes. ${ }^{18,56}$ Both murine and human BM-derived VSELs express several pluripotent stem cell markers, including Oct4, Nanog, Rex-1 and SSEA-1 (murine VSELs) or SSEA-4 (human VSELs). ${ }^{46,57}$

Studies performed on highly purified double-sorted VSELS isolated from murine BM revealed that these cells highly express, at the mRNA and/or protein levels, genes involved both in specification of the epiblast (for example, Stella, Prdm14, Fragilis, Blimp1, Nanos3 and Dnd1) and late-migratory PGCs (for example, Dppa2, Dppa4 and Mvh). ${ }^{58}$ Moreover, the main intrinsic molecular mechanisms that keep VSELs quiescent in adult tissues are similar to those that govern quiescence of PGCs and are based on epigenetic modification of some parentally imprinted genes. ${ }^{59}$ Specifically, VSELs, like post-migratory PGCs, modify the imprinting of certain early-development parentally imprinted gene loci, including Igf2- $\mathrm{H} 19$, which results in their resistance to insulin/ insulin like-growth factor (IIS) signaling, and, by modifying imprinting at the KCNQ1/p57 ${ }^{\mathrm{Kip} 2}$ locus, upregulate in parallel the cyclin-dependent kinase inhibitor p57 ${ }^{\mathrm{KIP2}}{ }^{58,60}$ We also observed significant differences in the expression of certain miRNA species, including (i) miRNA-675-3p, miRNA-675-5p, miRNA-292-5p, miRNA-184 and miRNA-125b, whose upregulation attenuates the abovementioned IIS signaling, and (ii) miRNA-25-1 and miRNA$-19 b$, whose downregulation has the effect of upregulating the cell cycle checkpoint. ${ }^{61}$ 
Therefore, the expression in VSELs of genes characteristic of migrating PGCs, ${ }^{62}$ the germline specification of VSELs, ${ }^{18,40}$ and the fact that similar epigenetic changes control the quiescent state of PGCs and VSELs in adult tissues due to modification of imprinting at regulatory regions in paternally imprinted genes, 58,60 all strongly support a potential developmental link between these cell populations. Other similarities include (i) the similar expression of functional receptors for erythropoietin ${ }^{60}$ and vitamin $D 3^{63}$ (ii) the hematopoietic specification of both types of cells, ${ }^{16,18,36}$ and (iii) the expression of several receptors for sex hormones (highlighted in this review). ${ }^{64,65}$

\section{FROM VSELS TO HSCS-NORMAL PHYSIOLOGY OR AN EMERGENCY PATHWAY?}

The phenotype of most primitive LT-HSCs is still not completely defined. Several potential candidate cells have been described based on cell-surface antigen expression and exclusion of fluorescent dyes. ${ }^{13,16}$ HSCs can be purified from BM, UCB and $\mathrm{mPB}$ by employing (i) characteristic stem cell antigens (for example, CD34 and CD133 in humans, and Sca-1 in mice), (ii) the absence of lineage differentiation markers (lin ${ }^{-}$), (iii) high expression of aldehyde dehydrogenase (ALDH), and (iv) low accumulation of Hoe3342 (Hoe3342 ${ }^{\text {low }}$ ), Pyronin Y (Pyronin $Y^{\text {low }}$ ), or Rhodamine 123 (Rh123 ${ }^{\text {low }}$ ) dyes. ${ }^{13}$ A combination of signaling lymphocyte activating molecule (SLAM) markers (CD150 ${ }^{+}, \mathrm{CD} 48^{-}$ and $\left(\mathrm{C} 244^{-}\right.$) has also been recently proposed for discriminating between primitive HSC populations. ${ }^{66}$

On the other hand, mounting evidence indicates that BM and other tissues contain rare, primitive stem cells that do not exhibit either in vitro or in vivo hematopoietic activity immediately after purification but may acquire hematopoietic potential under appropriate experimental settings. Examples of such cells include the following: (i) murine BM-derived SSEA- $1^{+} \mathrm{MSCs}^{67}$ (ii) skeletal

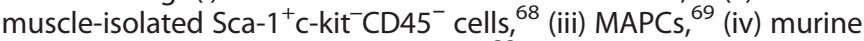
testis-derived multipotent germ cells ${ }^{38}$ and (v) fat tissue-derived CD45-negative cells. ${ }^{70}$ Moreover, by employing elutriation, a population of very small cells measuring $\sim 5 \mu \mathrm{m}$ in diameter can be isolated-at FR25 (flow rate $25 \mathrm{ml} / \mathrm{min}$ ) with $\mathrm{ALDH}^{\text {high }}$ Lin $^{-}$AA4.1 $1^{-}$markers - that do not radioprotect lethally irradiated mice and lack spleen colony-forming (CFU-S) activity, but if cotransplanted with short-term engrafting HSCs, produce delayed multilineage engraftment. ${ }^{71}$ These latter cells have been recently confirmed to overlap with VSELs, and thus we became interested in the hematopoietic potential of CD45-negative VSELs. ${ }^{15,16}$

My group found that, similar to FR25 $\mathrm{ALDH}^{\text {high }} \operatorname{lin}^{-} \mathrm{AA} 4.1^{-}$stem cells, ${ }^{71}$ VSELs freshly isolated from BM do not show any in vitro or in vivo hematopoietic activity in classical hematopoietic assays. Specifically, they do not grow colonies in methylcellulose and do not protect lethally irradiated animals, ${ }^{15}$ which is one of the gold standard assays for HSCs. VSELs, however, do acquire hematopoietic potential after co-culture over OP9 stromal cells, in a similar manner as embryonic and induced pluripotent stem cells. ${ }^{15,16}$ CD $45^{-}$VSELs in OP9 co-cultures differentiate into CD45 ${ }^{+}$ clonogenic hematopoietic progenitors but, more importantly, also into HSCs, which are able to establish long-term chimerism, both in primary as well as in secondary transplants. On the basis of these observations, we proposed that VSELs are the most primitive murine BM-residing population of stem cells that have the potential to become specified into the hematopoietic lineage and thus may share some of the characteristics of long-term repopulating HSCs (LT-HSCs). Hematopoietic differentiation of VSELs has been recently confirmed by other independent team. ${ }^{18}$

Moreover, taking into consideration the possibility that VSELs can give rise to hemangioblasts that possess both hematopoietic and endothelial potential, recent work from an independent group employing well-controlled experiments demonstrated the ability of VSELs to give rise both in vitro and in vivo to endothelium. ${ }^{19,51,52}$ In further support of this notion, we observed that VSELs highly express mRNA for the Flt-2 receptor (data not published).

\section{HEMATOPOIETIC STEM CELLS AND THEIR RESPONSIVENESS TO SEX HORMONES}

For a long time, the major problem with purified HSCs was that none of the proposed HSC populations ${ }^{72}$ could be efficiently expanded ex vivo to increase in cell number. Rather, all previously available HSC expansion protocols lead to an increase in the number of more differentiated hematopoietic progenitor cells, ${ }^{13,72}$ and there were two possible explanations for this fact. First, that we still have not identified all factors operating in vivo in HSC niches that are required for self-renewal of these cells, and second, that even these cells that have been claimed to be most primitive have already entered a pathway of differentiation at the expense of their true self-renewing potential. Recently, however, significant progress has been made in this direction both in experimental ${ }^{73-75}$ and clinical settings ${ }^{76}$ by employing prostaglandin $\mathrm{E}^{73}$ or small molecular compounds such as, for example, aryl hydrocarbon receptor antagonist - SR-1. ${ }^{76}$ Nevertheless, it is clear that in order to proceed with most optimal expansion, we should begin this process with the most primitive quiescent stem cell likely to be able to give rise to all these potential HSC candidates. I envision that such cells, which are at the top of the stem cell compartment hierarchy in adult BM, are VSELs because of all the reasons discussed above in this review (Figure 1a).

Therefore, based on the assumption that HSCs are derived from VSELs and most likely are direct descendants of PGCs migrating during embryogenesis, ${ }^{12,17,19,30}$ my group tested the responsiveness of HSCs to several factors that stimulate VSELs and PGCs. One group of such factors was the gonadal and pituitary sex hormones. Of note an important source of SexH during development is placenta. In our studies, while gonadal sex hormones, including androgens $s^{64,65}$ and, as recently reported by us and others, estrogens, ${ }^{64,77}$ stimulate murine and human hematopoiesis, the role of pituitary sex hormones, including follicle-stimulating hormone (FSH) and luteinizing hormone (LH), have not yet been investigated in more details. To address this issue, we tested the expression of receptors for pituitary-derived sex hormones, such as FSH, LH and PRL, on purified murine BM cells enriched for HSCs and tested the functionality of these receptors in ex vivo signal transduction studies and in vitro clonogenic assays. ${ }^{64,65}$ Addition of sex hormones in clonogenic assays performed in the presence of suboptimal doses of hematopoietic cytokines and growth factors increased the clonogenecity of hematopoietic progenitor cells from all major lineages. ${ }^{64,65}$ In parallel, we performed receptor expression studies with murine and human VSELs. ${ }^{64,65}$ We also tested in a mouse model whether administration of pituitary- and gonad-derived sex hormones increases incorporation of bromodeoxyuridine (BrdU) into HSCs and expansion of hematopoietic clonogenic progenitors in mice and promotes recovery of blood counts in sublethally irradiated animals. ${ }^{64} \mathrm{We}$ reported that murine and human HSCs, and VSELs express functional $\mathrm{FSH}$ and $\mathrm{LH}$ receptors and that both proliferate in vivo as evaluated by the number of BrdU-accumulating HSCs and in vitro clonogenic assays in response to stimulation by suboptimal doses of hematopoietic cytokines after addition of pituitary sex hormones. ${ }^{64,65}$ Human and murine HSCs also responded to stimulation by PRL. ${ }^{64,65}$ We have performed similar experiments with gonadal sex hormones, including androgens, estrogens and progesterone. In support of these findings, we detected expression of mRNA in purified murine Sca- $1^{+}$HSCs as well as in human purified $\mathrm{CD}_{3} 4^{+}$cells and demonstrated that these receptors are also expressed at the protein level and are functional, as indicated by phosphorylation of intermediates in the MAPKp42/44- and AKT-dependent signaling pathways. ${ }^{64,65}$ In 
a
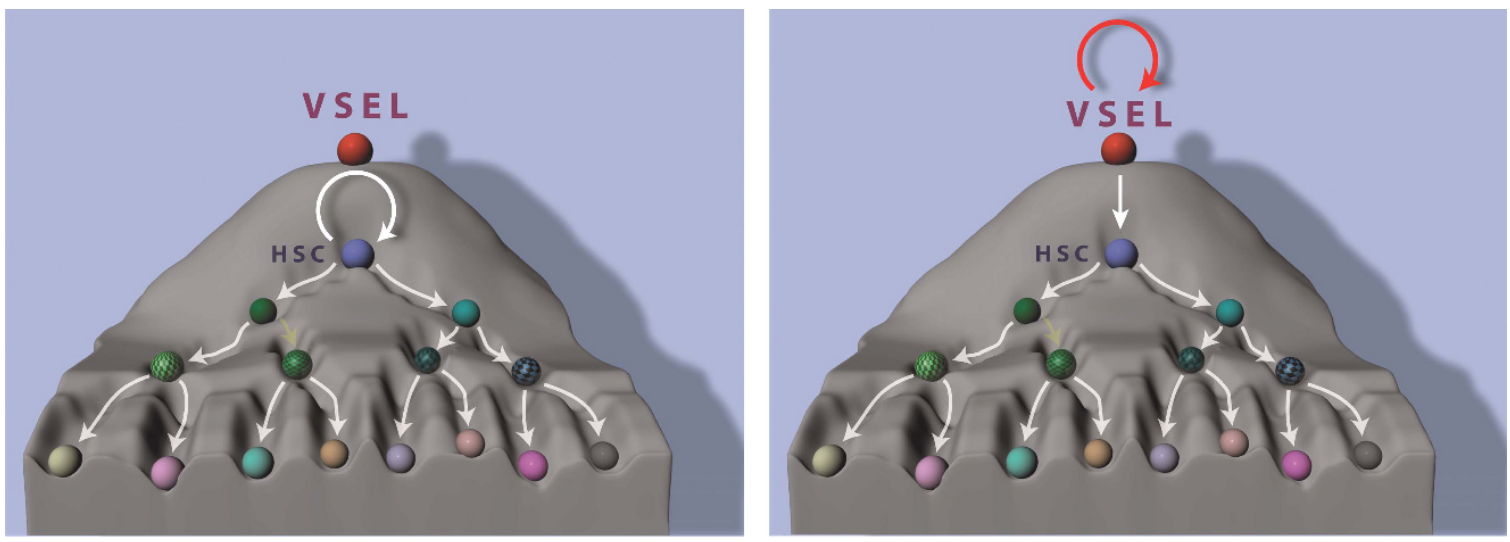

b PGC
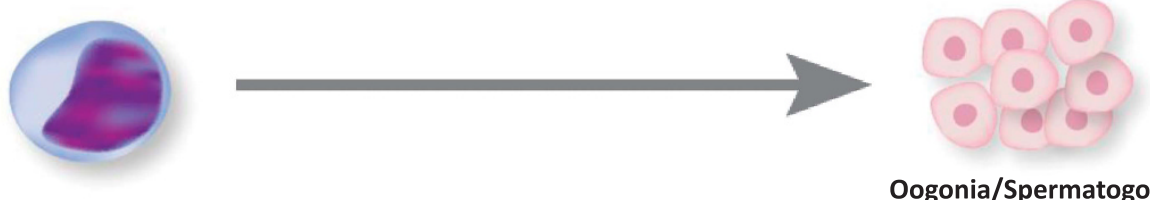

Oogonia/Spermatogonia Gametes
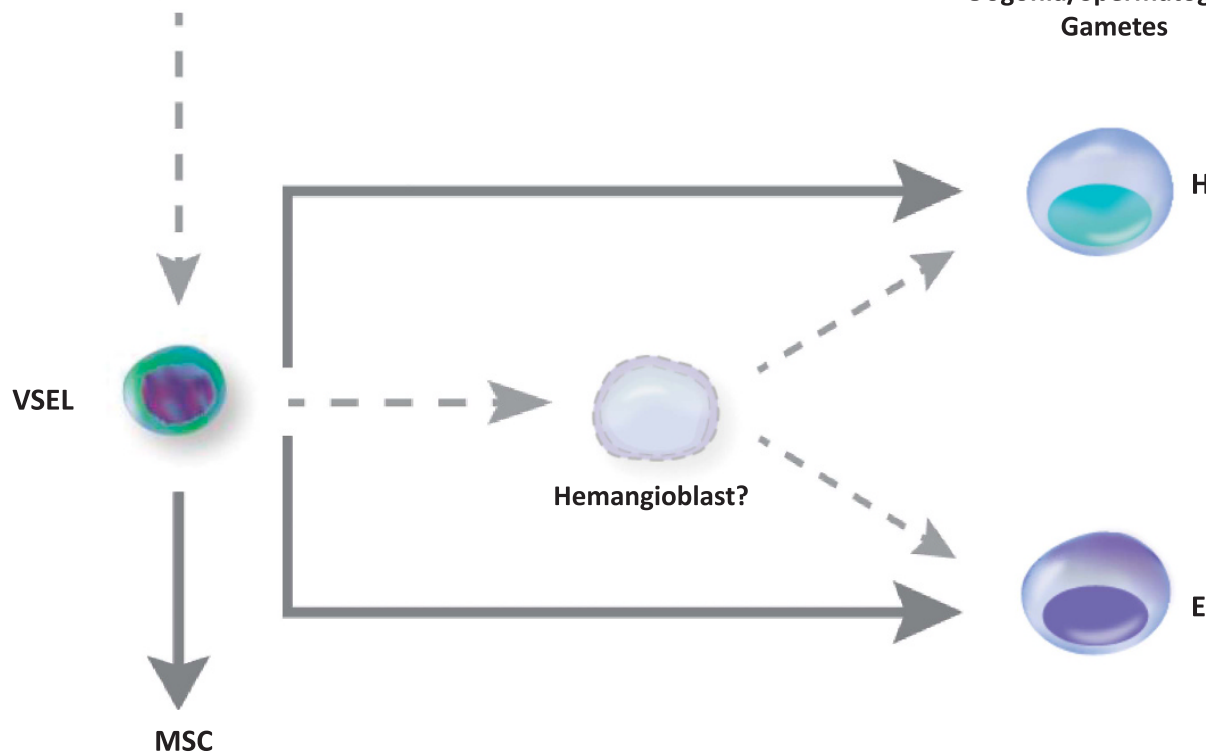

HSC

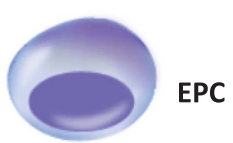

Other types of TCSCs

Figure 1. (a) A possible reason for the current poor results for clinical expansion of HSCs. It is most likely that the most of the current clinical expansion procedures employ HSCs that are already 'rolling downhill' in following a differentiation pathway (left panel). The expansion strategy should be better initiated at the level of VSELs, which are highly quiescent and positioned at the top of the stem cell compartment hierarchy (right panel). (b) Proposed developmental interrelationship between PGCs, VSELs, hemangioblasts, HSCs and EPCs. I propose that migratory primordial germ cells (PGCs), aside from their major role in establishing gametogenesis, may be a source of certain developmentally primitive stem cells (for example, VSELs) that give rise to hematopoietic stem cells (HSCs) and endothelial progenitor cells (EPCs) and are a source of other tissue-committed stem cells (TCSCs), such as for example, mesenchymal stem cells (MSCs). Specification of VSELs into HSCs and EPCs may involve putative hemangioblast as an intermediate precursor cell. VSEL-derived hematopoiesis may play a role under steadystate conditions in contributing to a pool of long-term repopulating HSCs and/or VSELs may become specified into HSCs during hematopoietic emergency stress situations. In support of this latter notion, the number of proliferating VSELs in BM increases in mice after acute bleeding. Dotted lines - concepts still under investigations.

experiments in mice in vivo, we found that administration of sex hormones increases the number of proliferating HSCs in $\mathrm{BM}^{64}$ and this is accompanied by an increase in BM-residing VSEL proliferation in vivo, which further supports the involvement of VSELs in hematopoiesis. ${ }^{64,65}$

\section{SEX HORMONES AND LEUKEMIA}

Sex hormones may also play a role in the pathogenesis of leukemia, as there are sex-dependent differences between males and females in the development of leukemia, lymphoma and myeloma, and males suffer more frequently from these disorders. $^{78}$

Nevertheless, the available literature on the potential role of $\mathrm{SexHs}$ in malignancies is mostly limited to the potential involvement of PRL, estrogen and androgen. ${ }^{79-83}$ For example, it has been reported that human $\mathrm{CD}_{3} 3^{+}$blasts express the PRL receptor (PRLR), and PRL is an oncogene in rat Nb2 lymphoma cells $^{84}$ and an autocrine growth factor for the human T-cell leukemia Jurkat cell line. ${ }^{85,86}$ On the other hand, estrogen 
receptors (ESRs) and androgen receptors (ARs) were detected in sex hormone binding studies in cells isolated from AML and CML patients in addition to human hematopoietic cell lines. ${ }^{87}$ Nevertheless, despite significant research effort, the effect of estrogens in leukemogenesis is somewhat controversial. For example, in support of ESR leukemia-promoting affects, the ESR gene promoter was found to be aberrantly hypermethylated in a majority of cases of pediatric ALL, adult ALL, adult $A M L$ and, in particular, blast crisis CML. ${ }^{87-90}$ By contrast, the disruption of ESR $\beta$ in mice causes myeloproliferative disease with lymphoid crisis, ${ }^{91}$ which suggests that estrogen signaling can control proliferation of hematopoietic cells. In support of the latter possibility, an ESR agonist has been found to have an anti-proliferative effect on the growth of lymphoma cells, ${ }^{92,93}$ and 17alpha-estradiol was reported to be toxic against the human Jurkat T-cell line. ${ }^{94}$ These observations may explain the protective effect of estrogens on hematopoietic malignancies in female patients, ${ }^{95}$ which correlates with the fact that females seem to be more resistant to leukemia. ${ }^{95}$

Nevertheless, while estrogens may have a protective role in developing leukemia and lymphoma, no evidence exists for a potential role of pituitary sex hormones, such as FSH and LH. This is important, as the FSH level increases with age as a result of gonadal dysfunction and lack of negative feedback from gonadal sex hormones, and it is known that age is one of the risk factors for developing hematopoietic malignancies. ${ }^{96,97}$

To address this issue, my team screened several human myeloid and lymphoid cell lines as well as leukemic AML and CML blasts isolated from patients for their expression of functional pituitary and gonadal sex hormone receptors. ${ }^{78}$ We found that FSH, LH, $\mathrm{PRL}$, androgen and progesterone (PRG) receptors were expressed by HEL, K562, THP-1, U937, KG-1a, HL-60 and DAMI cells. Human myeloid cell lines also expressed estrogen receptors alpha and beta (ESRa and $\beta$ ), with the exception of DAMI cells, which expressed ESR $\beta$ but not ESRa. Similarly, the lymphoid cell lines DAUDI, RAJI, NALM-6, JURKAT and MOLT4 expressed mRNA for FSH, LH, PRL, androgen and PRG receptors. At the same time, however, ESRa was not expressed by RAJl cells, and ESR $\beta$ mRNA expression was missing in the NALM-6 cell line. In parallel studies the FSH receptor was expressed by all $10 \mathrm{AML}$ blast samples and 5 out of $8 \mathrm{CML}$ blasts investigated by us. Moreover, while the mRNA for $\mathrm{LH}$ receptor was detectable by all $\mathrm{AML}$ and 4 out of $8 \mathrm{CML}$ patient-derived cells, the TPRL receptor was expressed in 8 out of 10 blast samples from $\mathrm{AML}$ patients and in all $8 \mathrm{CML}$ blast samples. Gonadal sex hormone receptor studies revealed that, while the AR was expressed in all AML and CML blast samples, 7 out of $10 \mathrm{AML}$ and 7 out of $8 \mathrm{CML}$ samples expressed ESRa, and 8 out of $10 \mathrm{AML}$ and all CML blast samples expressed ESR $\beta$. Finally, PGR was expressed in half of the AML and 3 of $8 \mathrm{CML}$ blast samples. ${ }^{78}$

In functional studies, we observed that FSH and LH stimulate migration, adhesion and proliferation of several human leukemia cell lines as well as AML and CML blasts isolated from patients. ${ }^{78}$ This effect seemed to be direct, as the receptors for these hormones responded to stimulation by phosphorylation of intracellular pathways involved in cell proliferation. We found that all of the myeloid cell lines as well as B and T lymphoid cell lines employed in our studies responded to sex hormones by chemotaxis in Transwell assays and by adhesion to fibronectincoated plates. Moreover, our proliferation studies, performed in $0.5 \%$ BSA with or without supplementation with SexHs, revealed that most of the leukemic cell lines employed in our study responded to stimulation by SexHs and that the highest responsiveness was observed to stimulation by the pituitary sex hormones (FSH, LH, and PRL), and a somewhat weaker response was observed after stimulation with PRG and estradiol. ${ }^{78}$

Finally, in in vivo experiments, when exposed to $\mathrm{FSH}$ or $\mathrm{LH}$ stimulation before intravenous injection into immunodeficient mice, human THP-1 leukemic cells showed increased seeding efficiency into murine BM, spleen, lung, and liver. ${ }^{78}$

\section{CONCLUSIONS}

Normal and malignant human HSCs as well as established hematopoietic cell lines express functional receptors not only for gonadal but also for pituitary and placental sex hormones. Expression of these receptors on HSCs suggests a potential developmental link between PGCs, VSELs and hematopoiesis (Figure 1b). In this context, it is proposed that VSELs are precursors of LT-HSCs, contributing to steady-state hematopoiesis and/or stress-induced hematopoiesis. In support of the latter possibility, BMP-4, a well-known PGC growth factor, has been reported to be involved in several models of stress hematopoiesis. ${ }^{98-100}$ We also found that intravenous injection of BMP-4 into mice increases BrdU accumulation in VSELs and HSCs (manuscript in preparation). As always, any challenging results or concepts as these discussed in the current review will need further studies and confirmation by additional independent groups.

\section{CONFLICT OF INTEREST}

The authors declare no conflict of interest.

\section{ACKNOWLEDGEMENTS}

This work was supported by NIH grants R01 DK074720, R01HL112788, the Stella and Henry Endowment and the Harmonia NCN grant UMO-2014/14/M/NZ3/00475 to MZR. Author is indebted to Dr Tomasz Jadczyk for graphical help with Figure.

\section{REFERENCES}

1 Jagannathan-Bogdan M, Zon LI. Hematopoiesis. Development 2013; 140 2463-2467.

2 Lux CT, Yoshimoto M, McGrath K, Conway SJ, Palis J, Yoder MC. All primitive and definitive hematopoietic progenitor cells emerging before E10 in the mouse embryo are products of the yolk sac. Blood 2008; 111: 3435-3438.

3 Baron $\mathrm{MH}$, Vacaru A, Nievesa J. Erythroid development in the mammalian embryo. Blood Cells Mol Dis 2013; 51: 1-15.

4 Mikkola HK, Orkin SH. The journey of developing hematopoietic stem cells. Development 2006; 133: 3733-3744.

5 De Miguel MP, Arnalich Montiel F, Lopez Iglesias P, Blazquez Martinez A, Nistal M. Epiblast-derived stem cells in embryonic and adult tissues. Int J Dev Biol 2009; 53: 1529-1540.

6 Palis J. Primitive and definitive erythropoiesis in mammals. Front Physiol 2014; 5: 3.

7 Hirschi KK. Hemogenic endothelium during development and beyond. Blood 2012; 119: 4823-4827.

8 North TE, de Bruijn MF, Stacy T, Talebian L, Lind E, Robin C et al. Runx1 expression marks long-term repopulating hematopoietic stem cells in the midgestation mouse embryo. Immunity 2002; 16: 661-672.

9 MFTR De Bruijn, Speck NA, Peeters MCE, Dzierzak E. Definitive hematopoietic stem cells first develop within the major arterial regions of the mouse embryo. EMBO J 2000; 19: 2465-2474.

10 Ivanovs A, Rybtsov S, Welch L, Anderson RA, Turner ML, Medvinsky A. Highly potent human hematopoietic stem cells first emerge in the intraembryonic aorta-gonad-mesonephros region. J Exp Med 2011; 208: 2417-2427.

11 De Felici M. Regulation of primordial germ cell development in the mouse. Int J Dev Biol 2000; 44: 575-580.

12 Virant-Klun I. Very Small embryonic-like stem cells: a potential developmental link between germinal lineage and hematopoiesis in humans. Stem Cells Dev 2016; 25: 101-113.

13 Ratajczak MZ. Phenotypic and functional characterization of hematopoietic stem cells. Curr Opin Hematol 2008; 15: 293-300.

14 Chung YS, Kim HJ, Kim TM, Hong SH, Kwon KR, An S et al. Undifferentiated hematopoietic cells are characterized by a genome-wide undermethylation dip around the transcription start site and a hierarchical epigenetic plasticity. Blood 2009; 114: 4968-4978.

15 Ratajczak J, Wysoczynski M, Zuba-Surma E, Wan W, Kucia M, Yoder MC et al. Adult murine bone marrow-derived very small embryonic-like stem cells 
differentiate into the hematopoietic lineage after coculture over OP9 stromal cells. Exp Hematol 2011; 39: 225-237.

16 Ratajczak J, Zuba-Surma E, Klich I, Liu R, Wysoczynski M, Greco N et al. Hematopoietic differentiation of umbilical cord blood-derived very small embryonic/ epiblast-like stem cells. Leukemia 2011; 25: 1278-1285.

17 Ratajczak MZ, Ratajczak J, Suszynska M, Miller DM, Kucia M, Shin DM. A novel view of the adult stem cell compartment from the perspective of a quiescent population of very small embryonic-like stem cells. Circ Res 2017; 120: 166-178.

18 Shaikh A, Anand S, Kapoor S, Ganguly R, Bhartiya D. Mouse bone marrow VSELs exhibit differentiation into three embryonic germ lineages and germ \& hematopoietic cells in culture. Stem Cell Rev 2017; 13: 202-216.

19 Smadja DM. Bone marrow very small embryonic-like stem cells: new generation of autologous cell therapy soon ready for prime time? Stem Cell Rev 2017; 13: 198-201.

20 Shirazi R, Zarnani AH, Soleimani M, Abdolvahabi MA, Nayernia K, Ragerdi Kashani I. BMP4 can generate primordial germ cells from bone-marrowderived pluripotent stem cells. Cell Biol Int 2012; 36: 1185-1193.

21 Johnson J, Bagley J, Skaznik-Wikiel M, Lee HJ, Adams GB, Niikura Y et al. Oocyte generation in adult mammalian ovaries by putative germ cell in bone marrow and peripheral blood. Cell 2005; 122: 303-315.

22 Selesniemi K, Lee HJ, Niikura T, Tilly JL. Young adult donor bone marrow infusions into female mice postpone age-related reproductive failure and improve off spring survival. Aging 2009; 1: 49-57.

23 Nayernia K, Lee JH, Drusenheimer N, Nolte J, Wulf G, Dressel R et al. Derivation of male germ cells from bone marrow stem cells. Lab Invest 2006; 86: 654-663.

24 Heo YT, Lee SH, Yang JH, Kim T, Lee HT. Bone marrow cell-mediated production of transgenic chickens. Lab Invest. 2011; 91: 1229-1240.

25 Liu C, Chen Z, Chen Z, Zhang T, Lu Y. Multiple tumor types may originate from bone marrow-derived cells. Neoplasia 2006; 8: 716-724.

26 Irie N, Tang WWC, Surani MA. Germ cell specification and pluripotency in mammals: a perspective from early embryogenesis. Reprod Med Biol 2014; 13: 203-215.

27 Ohinata Y, Payer B, O'Carroll D, Ancelin K, Ono Y, Sano M et al. Blimp1 is a critical determinant of the germ cell lineage in mice. Nature 2005; 436: 207-213.

28 Wallace DC, Chalkia D. Mitochondrial DNA genetics and the heteroplasmy conundrum in evolution and disease. Cold Spring Harb Perspect Biol 2013; 5: a021220.

29 Medvinsky A, Rybtsov S, Taoudi S. Embryonic origin of the adult hematopoietic system: advances and questions. Development 2011; 138: 1017-1031.

30 Scaldaferri ML, Klinger FG, Farini D, Di Carlo A, Carsetti R, Giorda E et al. Hematopoietic activity in putative mouse primordial germ cell populations. Mech Dev 2015; 136: 53-63.

31 Molyneaux K, Wylie C. Primordial germ cell migration. Int J Dev Biol 2004; 48: 537-544.

32 Ratajczak MZ, Schneider G, Suszynska M. Novel view of the adult stem cell compartment - of germline and parental imprinting. Int J Transl Sci 2016; 2015: $1-20$.

33 Koushik SV, Wang J, Rogers R, Moskhopidis D, Lambert NA, Creazzo TL et al. Targeted inactivation of the sodium-calcium exchanger (Ncx1) results in the lack of a heartbeat and abnormal myofibrillar organization. FASEB J 2001; 15: 1209-1211.

34 Palis J, Roberson S, Kennedy M, Wall C, Keller G. Development of erythroid and myeloid progenitors in the yolk sac and embryo proper of the mouse. Development 1999; 126: 5073-5084.

35 North TE, Goessling W, Peeters M, Li P, Ceol C, Lord AM et al. Hematopoietic stem cell development is dependent on blood flow. Cell 2009; 137: 736-748.

36 Rich IN. Primordial germ cells are capable of producing cells of the hematopoietic system in vitro. Blood 1995; 86: 463-472.

37 Ohtaka T, Matsui Y, Obinata M. Hematopoietic development of primordial germ cell-derived mouse embryonic germ cells in culture. Biochem Biophys Res Commun 1999; 260: 475-482.

38 Yoshimoto M, Heike T, Chang H, Kanatsu-Shinohara M, Baba S, Varnau JT et al. Bone marrow engraftment but limited expansion of hematopoietic cells from multipotent germline stem cells derived from neonatal mouse testis. Exp Hematol 2009; 37: 1400-1410.

39 Miwa Y, Atsumi T, Imai N, Ikawa Y. Primitive erythropoiesis of mouse teratocarcinoma stem cells PCC3/A/1 in serum-free medium. Development 1991; 111: 543-549.

40 Suszynska M, Poniewierska-Baran A, Gunjal P, Ratajczak J, Marycz K, Kakar SS et al. Expression of the erythropoietin receptor by germline-derived cells - further support for a potential developmental link between the germline and hematopoiesis. J Ovarian Res 2014; 7: 66.

41 Woodruff K, Wang N, May W, Adrone E, Denny C, Feig SA. The clonal nature of mediastinal germ cell tumors and acute myelogenous leukemia. a case report and review of the literatur. Cancer Genet Cytogenet 1995; 79: 25-31.
42 Chaganti RS, Ladanyi M, Samaniego F, Offit K, Reuter VE, Jhanwar SC et al. Leukemic differentiation of a mediastinal germ cell tumor. Genes Chromosomes Cancer 1989; 1: 83-87.

43 Nichols CR, Hoffman R, Einhorn LH, Williams SD, Wheeler LA, Garnick MB. Hematologic malignancies associated with primary mediastinal germcell tumors. Ann Intern Med 1985; 102: 603-609.

44 Fujiwara T, Dunn NR, Hogan BLM. Bone morphogenetic protein 4 in the extraembryonic mesoderm is required for allantois development and the localization and survival of primordial germ cells in the mouse. Proc Natl Acad Sci USA 2001; 98: 13739-13744.

45 Goldman DC, Bailey AS, Pfaffle DL, Al Masri A, Christian JL, Fleming WH. BMP4 regulates the hematopoietic stem cell niche. Blood 2009; 114: 4393-4401.

46 Kucia M, Halasa M, Wysoczynski M, Baskiewicz-Masiuk M, Moldenhawer S, Zuba-Surma $\mathrm{E}$ et al. Morphological and molecular characterization of novel population of CXCR4+ SSEA-4+ Oct-4+ very small embryonic-like cells purified from human cord blood: preliminary report. Leukemia 2007; 21: 297-303.

47 Ratajczak MZ, Shin DM, Ratajczak J, Kucia M, Bartke A. A novel insight into aging: are there pluripotent very small embryonic-like stem cells (VSELs) in adult tissues overtime depleted in an Igf-1-dependent manner? Aging (Albany NY) 2010; 2: 875-883.

48 Zuba-Surma EK, Kucia M, Abdel-Latif A, Dawn B, Hall B, Singh R et al. Morphological characterization of very small embryonic-like stem cells (VSELs) by ImageStream system analysis. J Cell Mol Med 2008; 12: 292-303.

49 Havens AM, Shiozawa Y, Jung Y, Sun H, Wang J, McGee S et al. Human very small embryonic-like cells generate skeletal structures, in vivo. Stem Cells Dev 2013; 22: 622-630.

50 Taichman RS, Wang Z, Shiozawa Y, Jung Y, Song J, Balduino A et al. Prospective identification and skeletal localization of cells capable of multilineage differentiation in vivo. Stem Cells Dev 2010; 19: 1557-1570.

51 Guerin CL, Loyer X, Vilar J, Cras A, Mirault T, Gaussem P et al. Bone-marrowderived very small embryonic-like stem cells in patients with critical leg ischaemia: evidence of vasculogenic potential. Thromb Haemost 2015; 113: 1084-1094.

52 Havens AM, Sun $H$, Shiozawa Y, Jung Y, Wang J, Mishra A et al. Human and murine very small embryonic-like cells represent multipotent tissue progenitors, in vitro and in vivo. Stem Cells Dev 2014; 23: 689-701.

53 Kassmer SH, Jin H, Zhang PX, Bruscia EM, Heydari K, Lee JH et al. Very small embryonic-like stem cells from the murine bone marrow differentiate into epithelial cells of the lung. Stem Cells 2013; 31: 2759-2766.

54 Kassmer SH, Bruscia EM, Zhang PX, Krause DS. Nonhematopoietic cells are the primary source of bone marrow-derived lung epithelial cells. Stem Cells 2012; 30: 491-499.

55 Wu JH, Wang HJ, Tan YZ, Li ZH. Characterization of rat very small embryonic-like stem cells and cardiac repair after cell transplantation for myocardial infarction. Stem Cells Dev 2012; 21: 1367-1379.

56 Virant-Klun I, Zech N, Rožman P, Vogler A, Cvjeticanin B, Klemenc P et al. Putative stem cells with an embryonic character isolated from the ovarian surface epithelium of women with no naturally present follicles and oocytes. Differentiation 2008; 76: 843-856.

57 Kucia M, Reca R, Campbell FR, Zuba-Surma E, Majka M, Ratajczak J et al. A population of very small embryonic-like (VSEL) CXCR4(+)SSEA-1(+)Oct-4+ stem cells identified in adult bone marrow. Leukemia 2006; 20: 857-869.

$58 \mathrm{Kim}$ YH, Jeong J, Kang H, Lim J, Heo J, Ratajczak J et al. The molecular nature of very small embryonic-like stem cells in adult tissues. Int J Stem Cells 2014; 7: 55-62.

59 Ratajczak MZ, Zuba-Surma E, Wojakowski W, Suszynska M, Mierzejewska K, Liu R et al. Very small embryonic-like stem cells (VSELs) represent a real challenge in stem cell biology: recent pros and cons in the midst of a lively debate. Leukemia 2014; 28: 473-484.

60 Shin DM, Zuba-Surma EK, Wu W, Ratajczak J, Wysoczynski M, Ratajczak MZ et al. Novel epigenetic mechanisms that control pluripotency and quiescence of adult bone marrow-derived Oct4(+) very small embryonic-like stem cells. Leukemia 2009; 23: 2042-2051.

61 Maj M, Schneider G, Ratajczak J, Suszynska M, Kucia M, Ratajczak MZ. The cell cycle- and insulin-signaling-inhibiting miRNA expression pattern of very small embryonic-like stem cells contributes to their quiescent state. Exp Biol Med 2015; 240: 1107-1111.

62 Shin DM, Liu R, Klich I, Wu W, Ratajczak J, Kucia M et al. Molecular signature of adult bone marrow-purified very small embryonic-like stem cells supports their developmental epiblast/germ line origin. Leukemia 2010; 24: 1450-1461.

63 Abdelbaset-Ismail A, Pedziwiatr D, Suszyńska E, Sluczanowska-Glabowska S, Schneider G, Kakar SS et al. Vitamin D3 stimulates embryonic stem cells but inhibits migration and growth of ovarian cancer and teratocarcinoma cell lines. J Ovarian Res 2016; 9: 26. 
64 Mierzejewska K, Borkowska S, Suszynska E, Suszynska M, Poniewierska-Baran A, Maj $\mathrm{M}$ et al. Hematopoietic stem/progenitor cells express several functional sex hormone receptors - novel evidence for a potential developmental link between hematopoiesis and primordial germ cells. Stem Cells Dev 2015; 24: 927-937.

65 Abdelbaset-Ismail A, Suszynska M, Borkowska S, Adamiak M, Ratajczak J, Kucia M et al. Human haematopoietic stem/progenitor cells express several functional sex hormone receptors. J Cell Mol Med 2016; 20: 134-146.

66 Kiel MJ, Yilmaz OH, Iwashita T, Terhorst C, Morrison SJ. SLAM family receptors distinguish hematopoietic stem and progenitor cells and reveal endothelial niches for stem cells. Cell 2005; 121: 1109-1121.

67 Anjos-Afonso F, Bonnet D. Nonhematopoietic/endothelial SSEA-1+ cells define the most primitive progenitors in the adult murine bone marrow mesenchymal compartment. Blood 2007; 109: 1298-1306.

68 Howell JC, Yoder MC, Srour EF. Hematopoietic potential of murine skeletal muscle-derived CD45(-)Sca-1(+)c-kit(-) cells. Exp Hematol 2002; 30: 915-924.

69 Serafini M, Dylla SJ, Oki M, Heremans Y, Tolar J, Jiang $Y$ et al. Hematopoietic reconstitution by multipotent adult progenitor cells: precursors to long-term hematopoietic stem cells. J Exp Med 2007; 204: 129-139.

70 Minana MD, Carbonell-Uberos F, Mirabet V, Marin S, Encabo A. IFATS collection: Identification of hemangioblasts in the adult human adipose tissue. Stem Cells. 2008; 26: 2696-2704.

71 Jones RJ, Collector MI, Barber JP, Vala MS, Fackler MJ, May WS et al. Characterization of mouse lymphohematopoietic stem cells lacking spleen colonyforming activity. Blood 1996; 88: 487-491.

72 Chou S, Chu P, Hwang W, Lodish H. Expansion of human cord blood hematopoietic stem cells for transplantation. Cell Stem Cell 2010; 7: 427-428.

73 North TE, Goessling W, Walkley CR, Lengerke C, Kopani KR, Lord AM et al. Prostaglandin E2 regulates vertebrate haematopoietic stem cell homeostasis. Nature 2007; 447: 1007-1011.

74 Boitano AE, Wang J, Romeo R, Bouchez LC, Parker AE, Sutton SE et al. Aryl hydrocarbon receptor antagonists promote the expansion of human hematopoietic stem cells. Science 2010; 329: 1345-1348.

75 Fares I, Chagraoui J, Gareau Y, Gingras S, Ruel R, Mayotte N et al. Cord blood expansion. Pyrimidoindole derivatives are agonists of human hematopoietic stem cell self-renewal. Science 2014; 345: 1509-1512.

76 Wagner JE Jr, Brunstein CG, Boitano AE, DeFor TE, McKenna D, Sumstad D et al. Phase I/II trial of stemregenin-1 expanded umbilical cord blood hematopoietic stem cells supports testing as a stand-alone graft. Cell Stem Cell 2016; 18: 144-155.

77 Nakada D, Oguro H, Levi BP, Ryan N, Kitano A, Saitoh Y et al. Oestrogen increases haematopoietic stem-cell self-renewal in females and during pregnancy. Nature 2014; 505: 555-558.

78 Abdelbaset-Ismail A, Borkowska S, Janowska-Wieczorek A, Tonn T, Rodriguez C, Moniuszko $\mathrm{M}$ et al. Novel evidence that pituitary gonadotropins directly stimulate human leukemic cells-studies of myeloid cell lines and primary patient AML and CML cells. Oncotarget 2016; 7: 3033-3046.

79 Anghel A, Narita D, Seclaman E, Popovici E, Anghel M, Tamas L. Estrogen receptor alpha polymorphisms and the risk of malignancies. Pathol Oncol Res 2010; 4: 485-496.

80 Meehan KL, Sadar MD. Androgens and androgen receptor in prostate and ovarian malignancies. Front Biosci 2003; 8: 780-800.

81 Cavlan D, Bharwani N, Grossman A. Androgen- and estrogen-secreting adrenal cancers. Semin Oncol 2010; 6: 638-648.

82 Levina WV, Nolen B, Su Y, Godwin AK, Fishman D, Liu J et al. Biological significance of prolactin in gynecologic cancers. Cancer Res 2009; 12: 5226-5233.

83 Hooghe R, Merchav S, Gaidano G, Naessens F, Matera L. A role for growth hormone and prolactin in leukaemia and lymphoma? Cell Mol Life Sci 1998; 10: 1095-1101.

84 Oberholtzer E, Contarini M, Veglia F, Cossarizza A, Franceschi C, Geuna M et al. Prolactin increases the susceptibility of primary leukemia cells to NK and LAK effectors. Adv Neuroimmunol 1996; 3: 233-247.
85 Matera L, Cutufia M, Geuna M, Contarini M, Buttiglieri S, Galin S et al. Prolactin is an autocrine growth factor for the Jurkat human T-leukemic cell line. J Neuroimmunol 1997; 1: 12-21.

86 Danel L, Martin P, Escrich E, Tubiana N, Fiere D, Saez S. Androgen, estrogen and progestin binding sites in human leukemic cells. Int J Cancer 1981; 6: 733-741.

87 Agrawal S, Unterberg M, Koschmieder S, zur Stadt U, Brunnberg U, Verbeek W et al. DNA methylation of tumor suppressor genes in clinical remission predicts the relapse risk in acute myeloid leukemia. Cancer Res 2007; 3: 1370-1377.

88 Herman JG, Jen J, Merlo A, Baylin SB. Hypermethylation-associated inactivation indicates a tumor suppressor role for p15INK4B. Cancer Res 1996; 4: 722-727.

89 Hess CJ, Errami A, Berkhof J, Denkers F, Ossenkoppele GJ, Nygren AO et al. Concurrent methylation of promoters from tumor associated genes predicts outcome in acute myeloid leukemia. Leuk Lymphoma 2008; 6: 1132-1141.

90 Yao J, Zhang XB, Zhang XL, Fu WL. Methylation status of oestrogen receptor alpha-A: a predictor of prognosis in leukaemias. Biosci Rep 2010; 4: 217-222.

91 Shim GJ, Wang L, Andersson S, Nagy N, Kis LL, Zhang Q et al. Disruption of the estrogen receptor beta gene in mice causes myeloproliferative disease resembling chronic myeloid leukemia with lymphoid blast crisis. Proc Natl Acad Sci USA 2003; 11: 6694-6699.

92 Medina KL, Garrett KP, Thompson LF, Rossi MI, Payne KJ, Kincade PW. Identification of very early lymphoid precursors in bone marrow and their regulation by estrogen. Nat Immunol 2001; 8: 718-724.

93 Thurmond TS, Murante FG, Staples JE, Silverstone AE, Korach KS, Gasiewicz TA. Role of estrogen receptor alpha in hematopoietic stem cell development and B lymphocyte maturation in the male mouse. Endocrinology 2000; 7: 2309-2318.

94 Jun DY, Park HS, Kim JS, Park W, Song BH, Kim HS et al. 17Alpha-estradiol arrests cell cycle progression at G2/M and induces apoptotic cell death in human acute leukemia Jurkat T cells. Toxicol Appl Pharmacol 2008; 3: 401-412.

95 Society ACCancer Facts \& Figures. 2014. Available at http://www.cancer.org/ research/cancerfactsstatistics/cancerfactsfigures2014/.

96 Klein NA, Illingworth PJ, Groome NP, McNeilly AS, Battaglia DE, Soules MR. Decreased inhibin $B$ secretion is associated with the monotropic FSH rise in older, ovulatory women: a study of serum and follicular fluid levels of dimeric inhibin A and B in spontaneous menstrual cycles. J Clin Endocrinol Metab 1996; 7: 2742-2745.

97 Wang YJ, Wu JC, Lee SD, Tsai YT, Lo KJ. Gonadal dysfunction and changes in sex hormones in postnecrotic cirrhotic men: a matched study with alcoholic cirrhotic men. Hepatogastroenterology 1991; 6: 531-534.

98 Vignjević S, Budeč M, Marković D, Dikić D, Mitrović O, Mojsilović S et al. Chronic psychological stress activates BMP4-dependent extramedullary erythropoiesis. J Cell Mol Med 2014; 18: 91-103.

99 Millot S, Andrieu V, Letteron P, Lyoumi S, Hurtado-Nedelec M, Karim Z et al. Erythropoietin stimulates spleen BMP4-dependent stress erythropoiesis and partially corrects anemia in a mouse model of generalized inflammation. Blood 2010; 116: 6072-6081.

100 Paulson RF, Shi L, Wu DC. Stress erythropoiesis: new signals and new stress progenitor cells. Curr Opin Hematol 2011; 18: 139-145.

(c) (1) (2) This work is licensed under a Creative Commons AttributionNonCommercial-ShareAlike 4.0 International License. The images or other third party material in this article are included in the article's Creative Commons license, unless indicated otherwise in the credit line; if the material is not included under the Creative Commons license, users will need to obtain permission from the license holder to reproduce the material. To view a copy of this license, visit http:// creativecommons.org/licenses/by-nc-sa/4.0/

(c) The Author(s) 2017 